\title{
Long-term tolerance and outcomes for dose escalation in early salvage post-prostatectomy radiation therapy
}

\author{
Joseph J. Safdieh, MD ${ }^{1,2}$, David Schwartz, MD ${ }^{1,2}$, Joseph Weiner, MD ${ }^{1,2}$, Jeffrey P. Weiss, MD ${ }^{1,2}$, \\ Justin Rineer, MD, Isaac Madeb, MD ${ }^{1,2}$, Marvin Rotman, MD ${ }^{1,2}$, David Schreiber, MD $D^{1,2}$ \\ 'Department of Veteran Affairs, New York Harbor Healthcare System, Brooklyn, NY; ${ }^{2}$ Department of Radiation Oncology, \\ SUNY Downstate Medical Center, Brooklyn, NY; ${ }^{3}$ University of Florida Health Cancer Center, Orlando, FL, USA
}

\begin{abstract}
Purpose: To study the long-term outcomes and tolerance in our patients who received dose escalated radiotherapy in the early salvage post-prostatectomy setting.

Materials and Methods: The medical records of 54 consecutive patients who underwent radical prostatectomy subsequently followed by salvage radiation therapy (SRT) to the prostate bed between 2003-2010 were analyzed. Patients included were required to have a pre-radiation prostate specific antigen level (PSA) of $2 \mathrm{ng} / \mathrm{mL}$ or less. The median SRT dose was $70.2 \mathrm{~Gy}$. Biochemical failure after salvage radiation was defined as a PSA level $>0.2 \mathrm{ng} / \mathrm{mL}$. Biochemical control and survival endpoints were analyzed using the Kaplan-Meier method. Univariate and multivariate Cox regression analysis were used to identify the potential impact of confounding factors on outcomes.

Results: The median pre-SRT PSA was $0.45 \mathrm{ng} / \mathrm{mL}$ and the median follow-up time was 71 months. The 4- and 7-year actuarial biochemical control rates were 75.7\% and 63.2\%, respectively. The actuarial 4- and 7-year distant metastasis-free survival was $93.7 \%$ and $87.0 \%$, respectively, and the actuarial 7 -year prostate cancer specific survival was $94.9 \%$. Grade 3 late genitourinary toxicity developed in 14 patients (25.9\%), while grade 4 late genitourinary toxicity developed in 2 patients (3.7\%). Grade 3 late gastrointestinal toxicity developed in 1 patient (1.9\%), and grade 4 late gastrointestinal toxicity developed in 1 patient (1.9\%).

Conclusion: In this series with long-term follow-up, early SRT provided outcomes and toxicity profiles similar to those reported from the three major randomized trials studying adjuvant radiation therapy.
\end{abstract}

Keywords: Dose escalation, Prostate cancer, Radiation therapy, Salvage

\section{Introduction}

Prostate cancer generally presents with localized disease amenable to cure via radical prostatectomy. However, although surgery provides excellent control rates, about 20\%-40\% will experience biochemical prostate specific antigen (PSA) failure $[1,2]$. Without salvage treatment, such as salvage radiation
(SRT), 34\% of men with biochemical failure will develop distant metastasis in 5 years, and median time to metastases has been reported to be 8 years from the time of biochemical failure [3]. While there have been 3 prospective randomized trials providing evidence in support of adjuvant radiation therapy, no prospective randomized trial has been published addressing the benefit of SRT. However, several retrospective studies have

Received 27 June 2014, Revised 5 August 2014, Accepted 21 August 2014.

Correspondence: Joseph J. Safdieh, MD, Department of Veteran Affairs, New York Harbor Healthcare System, 800 Poly Place, Brooklyn, NY 11209, USA. Tel: +1-718-630-3605, Email: Joseph.Safdieh@downstate.edu

(c) This is an Open Access article distributed under the terms of the Creative Commons Attribution Non-Commercial License (http://creativecommons.org/ licenses/by-nc/3.0/) which permits unrestricted non-commercial use, distribution, and reproduction in any medium, provided the original work is properly cited.

www.e-roj.org 
reported that SRT improves both cancer specific survival and overall survival in patients with PSA failure $[4,5]$.

For those who receive SRT, the role of dose escalated radiotherapy (RT) is not clear. Although dose escalation has been shown in prospective studies to improve biochemical survival in the definitive setting, dose escalation in the salvage setting has not been tested thoroughly. The three seminal retrospective studies used median radiation doses ranging between 64.8-66.5 Gy [4-6]. However, a recent meta-analysis suggests a benefit of $2 \%$ improvement in recurrence-free survival (RFS) for each additional gray administered in a salvage setting [7]. Therefore, the purpose of this study is to evaluate the outcomes and toxicities of patients treated with SRT at the New York Harbor Veterans Affairs Hospital with doses escalated to $70.2 \mathrm{~Gy}$.

\section{Materials and Methods}

After approval by the Department of Veterans Affairs New York Harbor Institutional Review Board, we retrospectively analyzed the medical records of patients who received surgery subsequently followed by radiation therapy to the prostate bed between 2003-2010 and had a pre-RT PSA level of $2 \mathrm{ng} / \mathrm{mL}$ or less. A total of 80 patients were identified. Seven patients were excluded for having a pre-RT PSA above $2 \mathrm{ng} / \mathrm{mL}$. An additional 16 patients were excluded for undergoing adjuvant radiation with an undetectable PSA rather than salvage and three patients were excluded for being treated with neoadjuvant or concurrent androgen deprivation. After exclusions, 54 patients were available for analysis.

The metastatic workup prior to the initiation of salvage radiation included a diagnostic CT scan for all patients to rule out pelvic adenopathy. Bone scans were ordered at the discretion of the treating physician but were generally ordered for patients who had clinically high risk disease and/ or a rapidly rising postoperative PSA. The radiation dose and technique varied over time. From 2003 through 2004, patients were treated exclusively with three-dimensional conformal radiation therapy (3D-CRT). Starting in late 2005, intensitymodulated radiation therapy (IMRT) came into use and by 2008 all patients were being treated exclusively with IMRT. Radiation fields consisted of the prostate bed alone for 30 patients. The remaining patients were initially treated to the true pelvis $(24$ patients) or the whole pelvis (3 patients) followed a cone down to the prostate bed. Patients treated with 3D-CRT generally received 6 field coplanar beams with $10 \mathrm{MV}$ photons, or an initial 4 field plan followed by a 6 field cone down. IMRT plans generally consisted of 7-9 coplanar beams using 6 or $10 \mathrm{MV}$ photons. The clinical target volumes were contoured per the Radiation Therapy Oncology Group (RTOG) guidelines [8] and included the caudal vas deferens remnant superiorly, the penile bulb inferiorly the obturator internus muscles laterally and the posterior aspect of the pubic symphysis and posterior $2 \mathrm{~cm}$ of the bladder wall anteriorly. For 3D-CRT plans a margin of $1.5 \mathrm{~cm}$ was placed around the clinical target volume to make the planning target volume, allowing additional room for penumbra. For IMRT plans, an 8-mm margin was placed all around the clinical target volume to make the final planning target volume. The median RT dose was 70.2 Gy and 43 patients (80\%) received this dose. The remaining patients received RT doses of 66.6 Gy (9 patients), 65 Gy (1 patient), or 63.8 Gy (1 patient).

We retrospectively reviewed all the medical records of these patients, including both the records from our clinics as well as other clinics within the nationwide Veterans Affairs system. Biochemical failure after salvage radiation was defined as a PSA level $>0.2 \mathrm{ng} / \mathrm{mL}$ followed by a confirmatory measurement or by the initiation of salvage androgen deprivation therapy. Distant failure was defined based on radiographic evidence of metastatic disease. Prostate cancer specific death was defined as patients who died from their disease or died from an undetermined cause but at last contact were known to have castrate resistant metastatic prostate cancer.

Follow-up time was calculated from the date that the radiation therapy treatments were completed. Patients were generally followed every 3-6 months for the first two years and then every 6-12 months thereafter. Toxicity was determined from the chart and was graded according to the National Cancer Institute Common Terminology Criteria for Adverse Events v3.0. Grade 1 toxicity corresponded to minimal side effects, grade 2 toxicity corresponded to side effects requiring medications, grade 3 corresponded to side effects requiring minor procedures or interventions, and grade 4 toxicity corresponded to medical admission due to life threatening complications. Differences in toxicities based on radiation therapy technique were compared using Fisher exact test. Biochemical control, distant control, and survival endpoints were analyzed using the Kaplan-Meier methods and compared using the log rank test. Univariate and multivariate Cox regression analysis was used to determine the potential impact of covariates on biochemical control and distant control endpoints. Statistical significance was defined as a 
Table 1. Patients' characteristics

\begin{tabular}{|c|c|}
\hline Parameter & No. (\%) \\
\hline \multicolumn{2}{|l|}{ Age (yr) } \\
\hline $51-60$ & $24(44.0)$ \\
\hline $61-70$ & $22(41.0)$ \\
\hline$>70$ & $8(15.0)$ \\
\hline \multicolumn{2}{|l|}{ pGleason } \\
\hline$\leq 6$ & $10(19.0)$ \\
\hline 7 & $35(65.0)$ \\
\hline $8-10$ & $5(9.0)$ \\
\hline Unknown & $4(7.0)$ \\
\hline \multicolumn{2}{|c|}{ Prostate specific antigen (ng/mL) } \\
\hline$<10$ & $36(67.0)$ \\
\hline $10.1-20$ & $12(22.0)$ \\
\hline$>20$ & $4(7.0)$ \\
\hline Unknown & $2(4.0)$ \\
\hline \multicolumn{2}{|l|}{ Pathologic T stage } \\
\hline $\mathrm{T} 2 \mathrm{a}-\mathrm{c}$ & $31(57.0)$ \\
\hline T3a & $10(19.0)$ \\
\hline $\mathrm{T} 3 b$ & $11(20.0)$ \\
\hline Unknown & $2(4.0)$ \\
\hline \multicolumn{2}{|l|}{ Margins } \\
\hline Negative & $19(35.0)$ \\
\hline Positive & $33(61.0)$ \\
\hline Unknown & $2(4.0)$ \\
\hline \multicolumn{2}{|l|}{ No. of positive margins } \\
\hline 0 & $19(35.0)$ \\
\hline 1 & $21(39.0)$ \\
\hline$\geq 2$ & $12(22.0)$ \\
\hline Unknown & $2(4.0)$ \\
\hline \multicolumn{2}{|l|}{ Perineural invasion } \\
\hline Yes & $31(57.0)$ \\
\hline No & $21(39.0)$ \\
\hline Unknown & $2(4.0)$ \\
\hline \multicolumn{2}{|l|}{ Lymphovascular invasion } \\
\hline Yes & $6(11.0)$ \\
\hline No & 46 (85.0) \\
\hline Unknown & $2(4.0)$ \\
\hline
\end{tabular}

*Numbers may not equal 100 due to rounding.

p-value $<0.05$. All analyses were carried our using SPSS ver. 21 (IBM, Armonk, NY, USA).

\section{Results}

The median follow-up time was 71 months (range, 17 to 127 months) and 96.3\% of patients were followed at least 2 years. The median PSA level at the time of radiation therapy was $0.45 \mathrm{ng} / \mathrm{mL}$ (range, 0.1 to $2.0 \mathrm{ng} / \mathrm{mL}$ ) and the median time from surgery to biochemical failure was 23.5 months (range,
Table 2. Salvage radiation therapy details

\begin{tabular}{lc}
\hline \multicolumn{1}{c}{ Parameter } & No. $(\%)$ \\
\hline Pre-radiation PSA (ng/mL) & \\
$\leq 0.5$ & $36(67.0)$ \\
$0.51-1.0$ & $14(26.0)$ \\
$>1$ & $4(7.0)$ \\
Time to failure (mo) & $18(33.0)$ \\
$1-12$ & $10(19.0)$ \\
$13-24$ & $14(26.0)$ \\
$25-60$ & $12(22.0)$ \\
$>60$ & \\
Treatment technique & $36(67.0)$ \\
3D-CRT & $18(33.0)$ \\
IMRT & \\
Fields & $3(6.0)$ \\
Whole pelvis & $23(43.0)$ \\
True pelvis & $28(52.0)$ \\
Prostate bed & \\
Dose (Gy) & $2(4.0)$ \\
63.8-65.0 & $9(17.0)$ \\
66.6 & $43(80.0)$ \\
70.2
\end{tabular}

Numbers may not equal 100 due to rounding. PSA, prostate specific antigen; 3D-CRT, three-dimensional conformal radiation therapy; IMRT, intensity-modulated radiation therapy.

1 to 91 months). There were 3 patients who were noted by the referring Urologist to have a rising PSA from undetectable level to $0.1 \mathrm{ng} / \mathrm{mL}$ and subsequently underwent salvage therapy. The remaining patients had a pre-RT PSA of 0.2 to $2 \mathrm{ng} / \mathrm{mL}$, which led to a referral for salvage radiation. Further details regarding patient and salvage radiation characteristics are available in Tables 1 and 2 .

\section{Biochemical and distant control outcomes}

There were a total of 17 biochemical failures at a median of 9 months post-RT (range, 0 to 75 months). The 4- and 7-year actuarial biochemical control rates were $75.7 \%$ and $63.2 \%$, respectively (Fig. 1). Of the 17 patients who had a biochemical recurrence, the median PSA value at the last follow-up was $1.90 \mathrm{ng} / \mathrm{mL}$ (range, 0 to $518 \mathrm{ng} / \mathrm{mL}$ ). There were 5 patients who developed distant metastatic disease. These patients were diagnosed with metastases at 10,35, 43, and 56 and 78 months after completing their radiation. The patient who was found to have metastases at 10 months remains alive at 70 months post-RT but with hormone refractory disease and a PSA of $518 \mathrm{ng} / \mathrm{mL}$. The patient who was found to have 


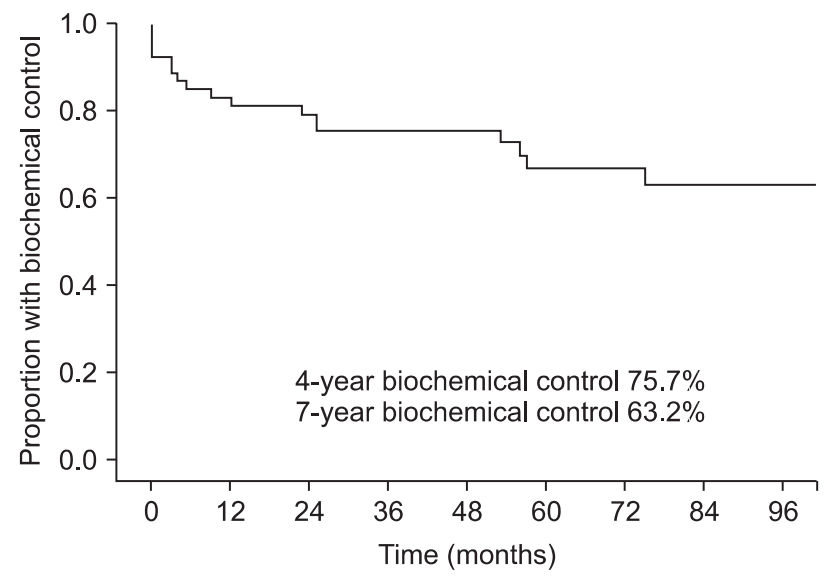

Fig. 1. The actuarial 4- and 7-year biochemical control rates.

distant metastases at 43 months post-RT also remains alive at 80 months post-treatment but also has hormone refractory disease with a PSA of $38.5 \mathrm{ng} / \mathrm{mL}$. The patient who developed metastases at 35 months ultimately died from prostate cancer at 40 months after his radiation treatments and the patient who developed metastases at 56 months died from prostate cancer at 60 months after completing his radiation treatments. The patient who developed metastases at 78 months was started on androgen deprivation and his most recent PSA is 0.0 $\mathrm{ng} / \mathrm{mL}$ at 94 months after completing his radiation treatments. The actuarial 4- and 7-year distant metastasis-free survival (DMFS) were $93.7 \%$ and $87.0 \%$, respectively (Fig. 2). The actuarial 7 -year prostate cancer specific survival was $94.9 \%$.

\section{Toxicity}

The radiation treatments were well tolerated in the short-term with minimal acute toxicities. Thirty-five patients (64.8\%) had grade 0-1 genitourinary toxicity and 19 patients had grade 2 toxicity consisting of dysuria in 7 patients, frequency in 8 patients, and urgency/hesitancy in 4 patients. In terms of short-term gastrointestinal toxicity, 40 patients $(74.1 \%)$ had grade $0-1$ toxicity. The remaining 14 patients all had grade 2 toxicity consisting of rectal pain/proctitis in 8 patients, diarrhea in 5 patients, and bleeding in one patient. There were no grade 3 or 4 acute toxicities.

In regards to late genitourinary toxicity, 37 patients (68.5\%) had grade 0-1 late urinary toxicity. One patients had grade 2 toxicity $(1.9 \%)$ consisting of urinary frequency. Fourteen patients developed grade 3 toxicity (25.9\%) consisting of urinary stricture requiring dilation in 10 patients, worsening incontinence in three patients, and cystitis requiring hyperbaric oxygen in one patient. Two patients (3.7\%) had grade 4

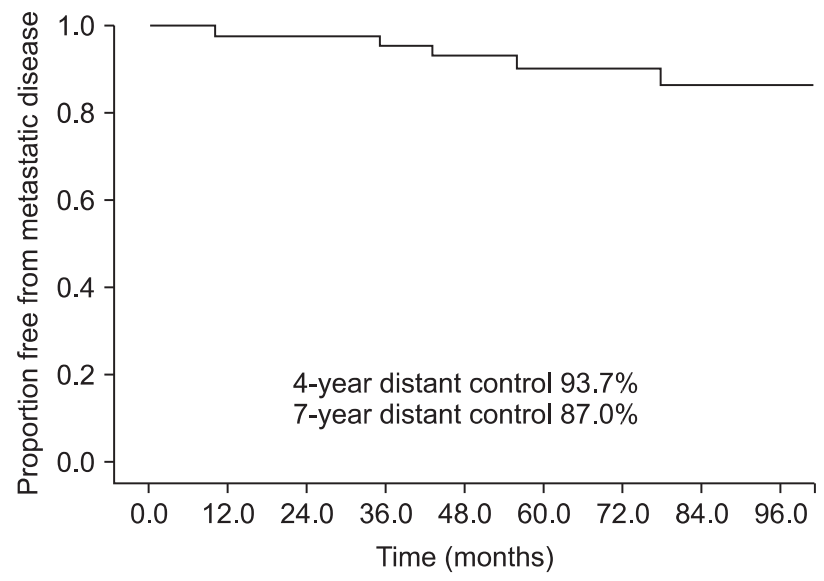

Fig. 2. The actuarial 4- and 7-year distant metastatic-free survival rates.

toxicity consisting of cystitis and hematuria requiring blood transfusions.

In regards to late gastrointestinal toxicity, 52 patients (96.3\%) had grade 0-1 late rectal toxicity. One patient (1.9\%) developed grade 3 proctitis that required argon plasma coagulation. Another patient developed grade 4 proctitis (1.9\%) that required blood transfusions. There were no grade 5 urinary or gastrointestinal toxicities.

We also analyzed the acute and late toxicities by radiation technique, in order to determine whether there was any improvement with the initiation of IMRT. There were no significant differences in toxicity based on the radiation treatment. However, with the exception of late gastrointestinal toxicity there appeared to be a trend towards a reduction in toxicity in those receiving IMRT. Further details are available in Table 3.

\section{Univariate and multivariate analyses}

On univariate analysis, a pre-RT PSA level $>0.4 \mathrm{ng} / \mathrm{mL}$ and perineural invasion were predictive for worse biochemical control while there was improved biochemical control with a radiation dose of $70.2 \mathrm{~Gy}$. On multivariate analysis, PSA level $>0.4 \mathrm{ng} / \mathrm{mL}$ and radiation dose of 70.2 Gy were statistically significant predictors for biochemical outcome. Further details are available in Table 4.

\section{Discussion and Conclusion}

This study of patients treated with dose escalated SRT after biochemical failure with a median PSA of $0.45 \mathrm{ng} / \mathrm{mL}$ reveals excellent long-term outcomes, with a 7-year actuarial 
biochemical control rate of 63.2\%, 7-year DMFS of $87.0 \%$, and

7 -year prostate cancer specific survival of $94.9 \%$.

It is difficult to directly compare our results to the prior

Table 3. Analysis of acute and late toxicities based on radiation technique

\begin{tabular}{lccc}
\hline Toxicity & 3D-CRT $(\mathrm{n}=36)$ & IMRT $(\mathrm{n}=18)$ & $\mathrm{p}$-value \\
\hline Acute GU & & & 0.55 \\
Grade 0-1 & $22(61.1)$ & $13(72.2)$ & \\
$\quad$ Grade 2 & $14(38.9)$ & $5(27.8)$ & \\
Acute GI & & & 0.11 \\
$\quad$ Grade 0-1 & $24(66.7)$ & $16(88.9)$ & \\
Grade 2 & $12(33.3)$ & $2(11.1)$ & \\
Late GU & & & 0.53 \\
Grade 0-2 & $24(66.7)$ & $14(77.8)$ & \\
Grade 3-4 & $12(33.3)$ & $4(22.2)$ & \\
Late Gl & & & 0.11 \\
Grade 0-2 & $36(100)$ & $16(88.9)$ & \\
Grade 3-4 & $0(0)$ & $2(11.1)$ & \\
\hline
\end{tabular}

Values are presented as number (\%).

GU, genitourinary; Gl, gastrointestinal; 3D-CRT, three-dimensional conformal radiation therapy; IMRT, intensity-modulated radiation therapy. randomized studies on adjuvant RT. In those studies the patients had not yet had a biochemical recurrence, so there are a number of patients who received RT that would not have needed it, as opposed to our study where all patients had to have a biochemical recurrence in order to receive SRT. Furthermore, the patient population in the randomized studies may not match ours in terms of pathologic stage of disease. Nevertheless, it should be noted that our biochemical control results with early salvage do appear similar to the data from the randomized trials on adjuvant RT. Wiegel et al. $[9,10]$ reported on patients with pT3-T4 patient with or without positive margins with undetectable PSA, which were randomized to RT to prostate bed to 60 Gy vs. observation. At 5- and 10-year biochemical progression-free survivals (bPFS) were $72 \%$ and $56 \%$ in the RT group, respectively. Bolla et al. $[11,12]$ randomized patients with PT2-T3 with extra capsular extension, seminal vesicle invasion or positive margin to observation vs. RT to $60 \mathrm{~Gy}$. The 5- and 10-year biochemical control rates were $74 \%$ and $60.6 \%$, respectively, in the patients who received adjuvant radiation. The Southwest Oncology Group (SWOG) reported results of a similar adjuvant trial which showed a bRFS at 5 and 10 years of $61 \%$ and $47 \%$ in

Table 4. Univariate and multivariate analysis for biochemical control

\begin{tabular}{|c|c|c|c|c|}
\hline & \multicolumn{2}{|c|}{ Univariate } & \multicolumn{2}{|c|}{ Multivariate } \\
\hline & HR (95\% Cl) & $p$-value & HR $(95 \% \mathrm{CI})$ & p-value \\
\hline \multicolumn{5}{|c|}{ Pre-RT PSA (ng/mL) } \\
\hline$\leq 0.4$ & 1 & & 1 & \\
\hline$>0.4$ & $4.05(1.31-12.49)$ & 0.02 & $6.40(1.57-26.02)$ & 0.01 \\
\hline \multicolumn{5}{|l|}{ Margins } \\
\hline Positive & $1.47(0.52-4.18)$ & 0.47 & $1.69(0.49-5.85)$ & 0.41 \\
\hline Negative & 1 & & 1 & \\
\hline \multicolumn{5}{|c|}{ Perineural invasion } \\
\hline Yes & $4.43(1.26-15.61)$ & 0.02 & $2.25(0.58-8.64)$ & 0.24 \\
\hline No & 1 & & 1 & \\
\hline \multicolumn{5}{|c|}{ Lymphovascular invasion } \\
\hline Yes & $2.00(0.57-7.04)$ & 0.28 & $2.55(0.57-11.37)$ & 0.22 \\
\hline No & 1 & & 1 & \\
\hline \multicolumn{5}{|l|}{ RT dose (Gy) } \\
\hline$<70.2$ & 1 & & 1 & \\
\hline 70.2 & $0.33(0.12-0.91)$ & 0.03 & $0.11(0.03-0.47)$ & 0.003 \\
\hline \multicolumn{5}{|c|}{ Extracapsular extension } \\
\hline Yes & $0.56(0.16-1.93)$ & 0.35 & $0.59(0.16-2.15)$ & 0.42 \\
\hline No & 1 & & 1 & \\
\hline \multicolumn{5}{|c|}{ Seminal vesicle invasion } \\
\hline Yes & $1.83(0.64-5.19)$ & 0.26 & $0.81(0.23-2.83)$ & 0.74 \\
\hline No & 1 & & 1 & \\
\hline
\end{tabular}

$\mathrm{HR}$, hazard ratio; $\mathrm{Cl}$, confidence interval; $\mathrm{RT}$, radiation therapy; PSA, prostate specific antigen. 
the patients that received adjuvant RT [13].

Our data also compares favorably to the DMFS reported in the adjuvant trials. Wiegel et al. [9] reported a 98\% DMFS with a median follow-up of 53.7 months. Bolla et al. [11] reported a 10 -year DMFS of $76.5 \%$ in the adjuvant RT group. SWOG reported 10 -year DMFS $71 \%$ in the patients receiving adjuvant RT [14].

There have been many retrospective studies published in the salvage setting and they too compare favorably to the current study. Stephenson et al. [6] analyzed 1,540 patients from 17 centers who received SRT with a median followup of 53 months and a median pre-RT PSA of $1.1 \mathrm{ng} / \mathrm{mL}$. The 6 -year overall progression-free probability (PFP) was 32\%. Neuhof et al. [15] analyzed 171 patients with biochemical failure after radical prostatectomy median with a Pre-RT PSA $1.1 \mathrm{ng} / \mathrm{mL}$ who were treated with SRT. With a median followup of 39 months, actuarial 3- and 5-year bRFS were $42.9 \%$ and 35.1\%. Pisansky et al. [16] analyzed 166 patients with a median follow-up of 52 months, and median Pre-RT PSA of $0.9 \mathrm{ng} / \mathrm{mL}$. They reported a 5 -year bRFS of $46 \%$ and relapsefree survival of 84\%. Goenka et al. [17] published the Memorial Sloan Kettering experience of salvage radiotherapy with a median PSA of $0.4 \mathrm{ng} / \mathrm{mL}$ and reported an actuarial 7-year PSA relapse-free survival and DMFS of $37 \%$ and $77 \%$, respectively.

Two potential reasons why our results appear stronger than some other retrospective studies may be that our patients had a very low median pre-RT PSA and that $80 \%$ of the patients in our study received dose escalation to $70.2 \mathrm{~Gy}$. The prognostic importance of Pre-RT PSA levels have been confirmed in multiple retrospective studies. Stephenson et al. [6] reported that when patients were stratified by pre-RT PSA, 6-year PFP was $48 \%$ for PSA $<0.5 \mathrm{ng} / \mathrm{mL}, 40 \%$ for PSA between $0.51-1.0$ $\mathrm{ng} / \mathrm{mL}, 28 \%$ for PSA between $1.01-1.5 \mathrm{ng} / \mathrm{mL}$, and $18 \%$ for PSA $>1.5 \mathrm{ng} / \mathrm{mL}$. Ost et al. [18] reported patients that received early salvage RT (Pre-RT PSA $<0.5 \mathrm{ng} / \mathrm{mL}$ ) had a significantly better bRFS than patients with late salvage RT (Pre-RT PSA >0.5 ng/ $\mathrm{mL}$ ). The 3-year bRFS was $86 \%$ for the early salvage vs. $46 \%$ for the late salvage $(p<0.001)$. Briganti et al. [19] reported on a multi-institutional cohort of 472 patients that received SRT with a PSA $\leq 0.5 \mathrm{ng} / \mathrm{mL}$. The 5 -year bRFS was noted to be $73.4 \%$. A recent collaborative review of the literature, which included 10 retrospective studies, confirmed these findings as well, reporting a 5 -year bRFS of $71.1 \%$ with $P S A \leq 0.5 \mathrm{ng} / \mathrm{mL}$ [20].

Dose escalation $>65 \mathrm{~Gy}$ in the salvage setting has also been shown in multiple retrospective studies to benefit biochemical control in the salvage setting. Bernard et al. [21] evaluated 364 patients with rising PSA after radical prostatectomy who received SRT between 1987 and 2007. Patients were stratified retrospectively by dose into low (<64.8 Gy), moderate (64.8$66.6 \mathrm{~Gy}$ ), and high (>66.6 Gy) and patients were followed for a median of 6.0 years. Cumulative results of 5 -year biochemical failure resulted in 57\%, 46\%, and 39\% for the low, moderate, and high dose groups, respectively, with a statistically significant difference between the low and the high groups ( $p$ $=0.04$ ). King et al. [22] compared a cohort of 122 patients who were treated with salvage radiation with a median dose of 60 Gy vs. 70 Gy and noted a significantly higher bRFS rate (58\% vs. $25 \%$; $p<0.0001)$. Contrarily, the Memorial Sloan Kettering Cancer Center experience comparing salvage radiation doses of $\geq 65$ to $\geq 70 \mathrm{~Gy}$, found that doses $\geq 70$ Gy did not precipitate improvement in biochemical control rates [16]. Current ASTRO/ AUA guidelines state that doses above 65 Gy can be safely delivered and may lead to improved tumor control [23]. In our study, receipt of 70.2 Gy did appear to correlate strongly with improved biochemical control on multivariate analysis, with a hazard ratio of 0.11 (95\% confidence interval, 0.03-0.47; p $=0.003$ ). However, as noted earlier, dose escalation would be expected to provide a relatively small incremental benefit in biochemical control [7]. Therefore, given the highly significant hazard ratio of 0.11 in this study, it seems likely that selection bias within our cohort is playing a role in this correlation rather than the impact of dose escalation alone.

Toxicity in our cohort is comparable to other reports of toxicity in the post-operative setting. The SWOG intergroup trial in the adjuvant setting reported rectal complications, such as proctitis or rectal bleeding in $3.3 \%$ of patient in the RT group. Urinary incontinence was noted to be about 6.5\% and urethral stricture 17.8\% with post-operative RT [24]. Our cohort correlates with the SWOG reported toxicity, with late grade 3-4 rectal toxicity noted to be $3.7 \%$, urinary incontinence in 5.6\% and urinary stricture in 18.5\% of patients. Three patients were noted to have grade 4 toxicities, 2 with grade 4 cystitis, and 1 with grade 4 proctitis, requiring blood transfusions. Perhaps with increased use of image guided radiotherapy, these toxicities, both in rate and grade would have decreased.

The present study has several limitations. Our study included 54 patients which is low in comparison to similar cohorts. The retrospective nature of this study predisposes itself to multiple possible biases, as noted earlier regarding the significance noted with higher SRT doses on multivariate analysis. In 
addition, there may have been other selection biases whereby patients who had a biochemical failure with more aggressive disease were treated with androgen deprivation alone and never referred for SRT. Finally, none of the patients in this cohort received androgen deprivation concurrently with their radiation therapy. Though the benefit of androgen deprivation has been clearly shown in the intact prostate setting, it is unclear whether it is beneficial in the salvage setting as well. Currently, the RTOG is enrolling patients in a randomized trial, RTOG 0534, that is evaluating both the proper radiation fields (prostate bed or whole pelvis) as well as the utility of 6 months of androgen deprivation in the salvage radiation setting.

However, despite its limitations and low patient numbers, this study does reveal that at a median follow-up of 71 months the efficacy of SRT is quite high if started early enough. The toxicity was not increased relative to other reports of SRT, despite an increase in the radiation dose. Further studies, preferably in a prospective nature, are needed to confirm these results.

In conclusion, this retrospective study found that dose escalation in the early salvage setting can lead to biochemical and distant metastasis-free survival outcomes that appear to be comparable to results achieved adjuvant setting. Since comparisons between salvage and adjuvant patients are flawed, particularly in the retrospective setting, randomized studies are needed to confirm these results.

\section{Conflict of Interest}

No potential conflict of interest relevant to this article was reported.

\section{References}

1. Han M, Partin AW, Pound CR, Epstein JI, Walsh PC. Longterm biochemical disease-free and cancer-specific survival following anatomic radical retropubic prostatectomy. The 15-year Johns Hopkins experience. Urol Clin North Am 2001;28:555-65.

2. Ward JF, Moul JW. Rising prostate-specific antigen after primary prostate cancer therapy. Nat Clin Pract Urol 2005:2:174-82.

3. Pound CR, Partin AW, Eisenberger MA, Chan DW, Pearson JD, Walsh PC. Natural history of progression after PSA elevation following radical prostatectomy. JAMA 1999;281:1591-7.

4. Trock BJ, Han M, Freedland SJ, et al. Prostate cancer-specific survival following salvage radiotherapy vs observation in men with biochemical recurrence after radical prostatectomy. JAMA 2008;299:2760-9.

5. Cotter SE, Chen MH, Moul JW, et al. Salvage radiation in men after prostate-specific antigen failure and the risk of death. Cancer 2011;117:3925-32.

6. Stephenson AJ, Scardino PT, Kattan MW, et al. Predicting the outcome of salvage radiation therapy for recurrent prostate cancer after radical prostatectomy. J Clin Oncol 2007;25:203541.

7. King CR. The timing of salvage radiotherapy after radical prostatectomy: a systematic review. Int J Radiat Oncol Biol Phys 2012;84:104-11.

8. Radiation Therapy Oncology Group contouring guidelines [Internet]. Philadelphia, PA: Radiation Therapy Oncology Group; c2014 [cited 2014 Jul 18]. Available from: http://www. rtog.org/CoreLab/ContouringAtlases/ProstatePost0p.aspx.

9. Wiegel T, Bottke D, Steiner $U$, et al. Phase III postoperative adjuvant radiotherapy after radical prostatectomy compared with radical prostatectomy alone in PT3 prostate cancer with postoperative undetectable prostate-specific antigen: ARO 96-02/AUO AP 09/95. J Clin Oncol 2009;27:2924-30.

10. Wiegel T, Bottke $D$, Bartkowiak $D$, et al. Phase III results of adjuvant radiotherapy (RT) versus wait-and-see (WS) in patients with $\mathrm{pT} 3$ prostate cancer following radical prostatectomy (RP)(AR0 96-02/AU0 AP 09/95): Ten years follow-up. J Clin Oncol 2013;30(Suppl 6):abstr 4.

11. Bolla M, van Poppel $H$, Collette $L$, et al. Postoperative radiotherapy after radical prostatectomy: a randomized controlled trial (EORTC trial 22911). Lancet 2005;366:572-8.

12. Bolla M, van Poppel $H_{1}$ Tombal $B$, et al. Postoperative radiotherapy after radical prostatectomy for high-risk prostate cancer: long-term results of a randomised controlled trial (EORTC trial 22911). Lancet 2012;380:2018-27.

13. Swanson GP, Thompson IM, Tangen $C$, et al. Phase III randomized study of adjuvant radiation therapy versus observation in patients with pathologic T3 prostate cancer (SWOG 8794). Int J Radiat Oncol Biol Phys 2005;63(Suppl 1);S1.

14. Thompson IM, Tangen CM, Paradelo J, et al. Adjuvant radiotherapy for pathological T3NOMO prostate cancer significantly reduces risk of metastases and improves survival: long-term followup of a randomized clinical trial. J Urol 2009;181:956-62.

15. Neuhof $D$, Hentschel T, Bischof M, Sroka-Perez G, Hohenfellner $M$, Debus J. Long-term results and predictive factors of threedimensional conformal salvage radiotherapy for biochemical relapse after prostatectomy. Int J Radiat Oncol Biol Phys 2007;67:1411-7.

16. Pisansky TM, Kozelsky TF, Myers RP, et al. Radiotherapy for isolated serum prostate specific antigen elevation after prostatectomy for prostate cancer. J Urol 2000;163:845-50. 
17. Goenka A, Magsanoc JM, Pei X, et al. Long-term outcomes after high-dose postprostatectomy salvage radiation treatment. Int J Radiat Oncol Biol Phys 2012;84:112-8.

18. Ost P, De Troyer B, Fonteyne V, Oosterlinck W, De Meerleer G. A matched control analysis of adjuvant and salvage high-dose postoperative intensity-modulated radiotherapy for prostate cancer. Int J Radiat Oncol Biol Phys 2011;80:1316-22.

19. Briganti A, Karnes RJ, Joniau S, et al. Prediction of outcome following early salvage radiotherapy among patients with biochemical recurrence after radical prostatectomy. Eur Urol 2013 Dec 12 [Epub]. http://dx.doi.org/10.1016/ j.eururo.2013.11.045.

20. Pfister $D$, Bolla $M$, Briganti $A$, et al. Early salvage radiotherapy following radical prostatectomy. Eur Urol 2014;65:1034-43.
21. Bernard JR Jr, Buskirk SJ, Heckman MG, et al. Salvage radiotherapy for rising prostate-specific antigen levels after radical prostatectomy for prostate cancer: dose-response analysis. Int J Radiat Oncol Biol Phys 2010;76:735-40.

22. King CR, Spiotto MT. Improved outcomes with higher doses for salvage radiotherapy after prostatectomy. Int J Radiat Oncol Biol Phys 2008;71:23-7.

23. Valicenti RK, Thompson I Jr, Albertsen $P$, et al. Adjuvant and salvage radiation therapy after prostatectomy: American Society for Radiation Oncology/American Urological Association guidelines. Int J Radiat Oncol Biol Phys 2013;86:822-8.

24. Thompson IM Jr, Tangen CM, Paradelo J, et al. Adjuvant radiotherapy for pathologically advanced prostate cancer: a randomized clinical trial. JAMA 2006;296:2329-35. 